\title{
First report of Alternaria alternata infection of kiwifruit in Turkey
}

\author{
Aziz Karakaya • Arzu Çelik
}

Received: 20 June 2012 / Accepted: 10 October 2012 / Published online: 23 October 2012

(C) Australasian Plant Pathology Society Inc. 2012

\begin{abstract}
A leaf spot disease of kiwifruit caused by Alternaria alternata is reported for the first time from Turkey.
\end{abstract}

Keywords Alternaria alternata $\cdot$ Actinidia deliciosa . Kiwifruit $\cdot$ Rize $\cdot$ Turkey

During the surveys of kiwifruit (Actinidia deliciosa (A. Chev.) C. F. Liang \& A. R. Ferguson) cv. Hayward in 2009 and 2010 in Rize province of Turkey, small, necrotic leaf spots were commonly observed (Fig. 1). The leaf spot was observed in the Rize central, Çayeli, Pazar and Ardeșen districts. The fungus isolated from the infected leaves, on potato dextrose agar, was identified as Alternaria alternata (Nees:Fr.) Keissl, based on conidial morphological characteristics (Simmons 2007). Pathogenicity tests were performed in a controlled growth room with a $18 / 23{ }^{\circ} \mathrm{C}$ night/day temperature regime. The relative humidity of the controlled growth room ranged between $65 \%$ and $85 \%$ during the experimental period. Pathogenicity studies were performed with 2 year-old kiwifruit plants cv. Hayward. Mycelial plugs, $0.5 \mathrm{~cm}$ in diameter, taken from a 10 day-old $A$. alternata culture were placed on the fully expanded kiwifruit leaves and removed 1 week later. In control treatments only sterile agar plugs were used. The leaves were misted three times each day for

A. Karakaya $(\bowtie) \cdot$ A. Çelik

Faculty of Agriculture, Department of Plant Protection,

University of Ankara,

Dışkap1, Ankara 06110, Turkey

e-mail: karakaya@agri.ankara.edu.tr
3 days. Four weeks after inoculation, necrotic areas, ca. 4-mm in diameter, were observed on the inoculated leaves. A. alternata was reisolated from the diseased regions. No disease was observed with the control plants. Cultures of Alternaria alternata are deposited in a herbarium at the Ankara University, Faculty of Agriculture, Department of Plant Protection, Turkey and in the Gazi University herbarium (GAZI), Ankara, Turkey (GAZI herbarium no: A. Karakaya 1046). Alternaria alternata was reported from Italy and Greece as the causal agents of leaf spot and dieback of kiwifruits (Corazza et al. 1999; Tsahouridou and Thanassoulopoulos 2000). This is the first report of

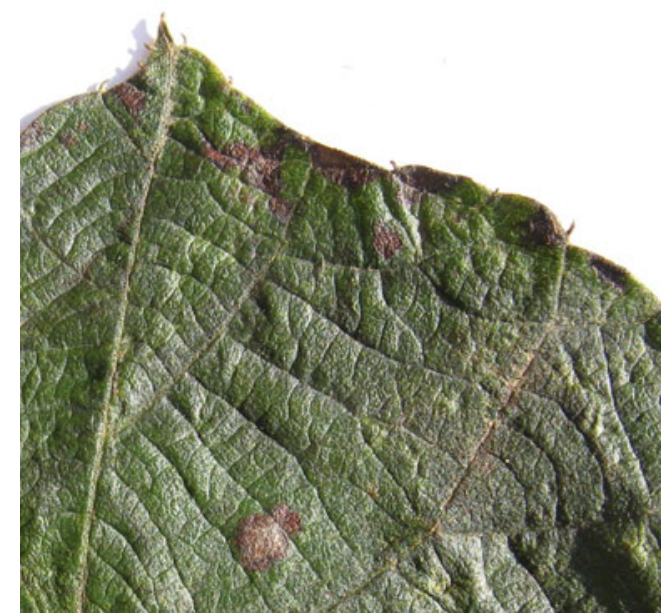

Fig. 1 Leaf spot symptoms caused by Alternaria alternata observed in kiwifruit orchards in Rize, Turkey 
Alternaria alternata causing disease in kiwifruit in Turkey.

Acknowledgments This study was supported by the Ankara University Research Fund (Project No: 08B4347002). The authors thank to members of the Ministry of Food, Agriculture and Animal Husbandry, Plant Protection Section, Rize Branch, Turkey, for their help during this study, and to Professor Mecit Vural of Gazi University for his help during the preparation of the herbarium sample.

\section{References}

Corazza L, Luongo L, Parisi M (1999) First report of leaf spot caused by Alternaria alternata on kiwifruit in Italy. Plant Disease 83:487

Simmons EG (2007) Alternaria-an 1dentification manual. CBS Fungal Biodiversity Centre, Utrecht, p 775

Tsahouridou PC, Thanassoulopoulos CC (2000) First report of Alternaria alternata as a dieback pathogen of kiwifruit. Plant Disease $84: 371$ 